\title{
Concept Formation Processes regarding Height and Base in Triangles
}

\author{
Felicitas Pielsticker ${ }^{1 *}$ (D)
}

${ }^{1}$ University of Siegen, GERMANY

*Corresponding Author: pielsticker@mathematik.uni-siegen.de

Citation: Pielsticker, F. (2021). Concept Formation Processes regarding Height and Base in Triangles. International Electronic Journal of Mathematics Education, 16(2), em0633. https://doi.org/10.29333/iejme/10891

\begin{tabular}{|c|c|}
\hline ARTICLE INFO & ABSTRACT \\
\hline Received: 5 Oct. 2020 & ncept formation processes of a student in the field of geometry. More precisely, the paper \\
\hline Accepted: 9 Feb. 2021 & $\begin{array}{l}\text { deals with the question of how to assist a student in a mathematical concept formation process - in the context } \\
\text { of area calculations in triangles - with a specially designed learning environment based on the usage of 3D printed } \\
\text { objects. Methodologically, we use the descriptive framework of the concept of Domains of Subjective Experience } \\
\text { for the analysis of our case study. The objective is to describe the use of a learning environment to initiate targeted, } \\
\text { theoretical concepts with a student. The student develops an empirical notion of bases and heights in triangles } \\
\text { (with respect to the calculation of surface areas), using 2D drawings and 3D printed objects. In this article we argue, } \\
\text { teaching mathematics consistently in an object-oriented and practical (visual) way, and additionally promoting } \\
\text { the development of concept formation as a mathematical activity, brings a student in a situation where he } \\
\text { develops hypotheses, tries them out, and transfers them to other fields of application; thus engages in concept }\end{array}$ \\
\hline
\end{tabular}

Keywords: concept formation processes, empirical objects, 3D printing

\section{INTRODUCTION}

Technology and digital media extend the range of possibilities of teaching and learning Mathematics. In current math class, a material-oriented, descriptive, and illustrative way of teaching and learning for various reasons has often been discussed (Thompson, 1994). For this reason, it is interesting how students develop their knowledge on these manipulatives (like for example $3 \mathrm{D}$ printed objects). There are already some studies that deal with issues relating to 3D printing in mathematics lessons (Dilling \& Witzke, 2020; Ng, 2017; Ng et al., 2018). Some with a focus on the use of 3D printing and the learning of geometry (Panorkou \& Pratt, 2016). A discussion about problems and potentials of representation (MacDonald et al., 2020) (also in connection with digital media) are often in the focus.

This article looks at an example taken from a study conducted in a German secondary school showing how a student ( $8^{\text {th }}$ grade) develops mathematical knowledge and engages in concept formation processes using specific 3D printed objects. Within a learning environment designed for this study focusing on the concept development of bases and heights in the context of area calculations in triangles, we discuss exemplarily the extent to which a student develops hypotheses, tries them out, transfers them to other fields of application, and engages in concept formation processes when mathematics is consistently taught in an objectoriented and practical (visual) way. We argue that the exploratory use of self-created objects is challenging the knowledge of a student and has an impact on the learning process of the student of our case study. The learning environment of the study is aligned with the following aspects of the National Council of Teachers of Mathematics (NCTM). According to the National Council of Teachers of Mathematics (NCTM, 2000) students in an $8^{\text {th }}$ grade class should generally be able to "analyze characteristics of geometric shapes and make mathematical arguments about the geometric relationship" (p. 3). It should be possible for students to create and to "use visualization" (p. 3), as well as to develop "reasoning and justification skills" (p. 3). For this purpose, an understanding of measurable attributes of objects must also be established. Students in an $8^{\text {th }}$ grade class should be able to understand the concept of measurement "as well as applying the techniques, tools and formulas" (p. 3). Thus, various aspects of NCTM play a role in our learning environment.

Our goal is to describe the use of a learning environment (a different context based on the usage of 3D printed objects) to initiate targeted, theoretical concepts with a student. The focus is on the following research question:

How to assist a student in a mathematical concept formation process - in the context of area calculations in triangles - with a specially designed learning environment based on the usage of 3D printed objects?

We make use of the descriptive approach of Domains of Subjective Experience (Bauersfeld, 1988) to describe our case and the exploratory processes in detail. 


\section{DATA COLLECTION AND METHOD}

The data collection was carried out by videotaping the learning environment based on the usage of new media in the context of area calculations in triangles. The learning environment in the field of geometry in an $8^{\text {th }}$ grade from an average rural German secondary school comprised two lessons (each 60 minutes). The learning environment consisted of two phases. A joint teaching phase (1) and a subsequent individual work phase (2). In the first phase the entire students of the class should determine surfaces areas of different triangles. In the second phase, the pupils under consideration received 3D printed triangles as a challenge.

In our intrinsically motivated case study, we describe a student, Paul (an 8th grade student, 13 years old), who completed both phases. Both phases were videotaped. The video material was then transcribed according to the rules of Meyer (2010).

Paul was noticed because he is quite familiar with mathematics lessons including the extensive use of physical objects (manipulatives). In particular, Paul was chosen for our intrinsically motivated case study because he seemed very confident in his knowledge of calculating areas in triangles. He also represented his concepts very clearly to classmates and was able to clarify appropriate arguments for his ideas. We wanted to find out why (Taber, 2014). It is therefore a specific case about which we wish to know about. Therefore the "case is given [...] we need to learn about that particular case (Stake, 1995, p.3).

Therefore, Paul's knowledge should be challenged using 3D printed objects with regard to concept formation processes. Against this background, it was remarkable to us how Paul deals with the context of the 3D printed objects for his knowledge development.

For the analysis of the specifics in the student concept formation processes while dealing with the 3D printed manipulatives we use a descriptive perspective. Therefore, we make use of two theoretical concept described in the following section.

\section{A Descriptive Perspective - Domain of Subjective Experience}

The concept of Domains of Subjective Experience (DSE) according to Bauersfeld (1983) can be used to describe the concept formation processes of the student when working with 3D printed manipulatives in the empirical case study. It allows us to describe how students develop their knowledge in a constructivist and interactionist sense. According to this theoretical framework learning is a domain-specific process and can be described as bound to a specific situation and a specific context (Bauersfeld, 1983). A DSE includes meaning, language, objects, and actions and encompasses both cognitive and motor or emotional dimensions. In this article, we focus on the cognitive dimension of the DSE of the student Paul. DSEs are organized nonhierarchical, cumulative and compete for activation. Furthermore, a repetition of a similar situation leads to a consolidation and a more effective activation of an DSE. According to Bauersfeld, "learning is characterized by the subjective reconstruction of social means and models through the negotiation of meaning in social interaction and in the course of related personal activities. New knowledge, then, is constituted and arises in the social interaction of members of a social group (culture), whose accomplishments reproduce as well as transmute the culture" (Bauersfeld, 1988, p. 39).

Language plays an important role in linking separate DSE. But each DSE has a specific language use (Tiedemann, 2016). A generalization of terms in this description is therefore mainly achieved managing a cognitive conflict (e.g., as a concrete goal of the teacher), so that, for example, an analogy can be formed and common mathematical contents of two different DSE can be recognized. For this process, a newly formed DSE is needed that enables the analogy to be recognized. That happens through a spontaneous interactive constitution of meaning by the learner (Bauersfeld, 1983). So that the formation of connections between mathematical structures does not appear to be trivial for the development of mathematical concepts.

With the help of the concept of DSE, we want to describe and analyze the concept formation processes of Paul in the context of area calculations in triangles - with a specially designed learning environment based on the usage of 3D printed objects. As Dilling and Witzke (2020, p. 18) point out, it is important that "the descriptions of the [...] empirical objects [...] the virtual 3Dmodels and the 3D-printed models, [...] [are the] objects of reference [which] constituted the [DSEs]". At the same time, the actions and terms used on the empirical objects also play a decisive role. Therefore, there is a focus on the empirical objects used by the student Paul and the language and terms, because we not only have "to analyze objects that we use in mathematics classes, but we have to analyze children's associations with them, too" (Fetzer \& Tiedemann, 2018, p. 1290). The concept of DSE focusses on the description of object-oriented concept formation processes, as well as the generation of connections between the DSES.

\section{THEORETICAL FRAMEWORK}

The basis of the analysis presented in this article is a constructivist view on learning processes - namely the idea that students construct their mathematical knowledge by themselves in interaction with their environment. This is supported by the approach of Hefendehl-Hebeker (2016), who says that the concepts and contents of school mathematics have their phenomenological sources predominantly in our surrounding reality. Today it is generally acknowledged that students constitute their own mathematical knowledge in action and negotiation processes (Krummheuer, 1984). This implies teaching concepts focusing on students' explorations (Holland, 2007; Vollrath, 1984). Learning in this sense is understood as an active process, dependent on individual experiential areas, constructing theories for an adequate cognition of certain phenomena (Burscheid \& Struve, 2020). Looking at approaches from cognitive psychology (e.g., "Theory theory" by Alison Gopnik), in particular the idea that "children develop abstract, coherent, systems of entities and rules, particularly causal entities and rules, [...] they develop theories" (Gopnik, 2003, p. 5), it seems to be quite reasonable to describe the behavior of students in the sense of theories. 


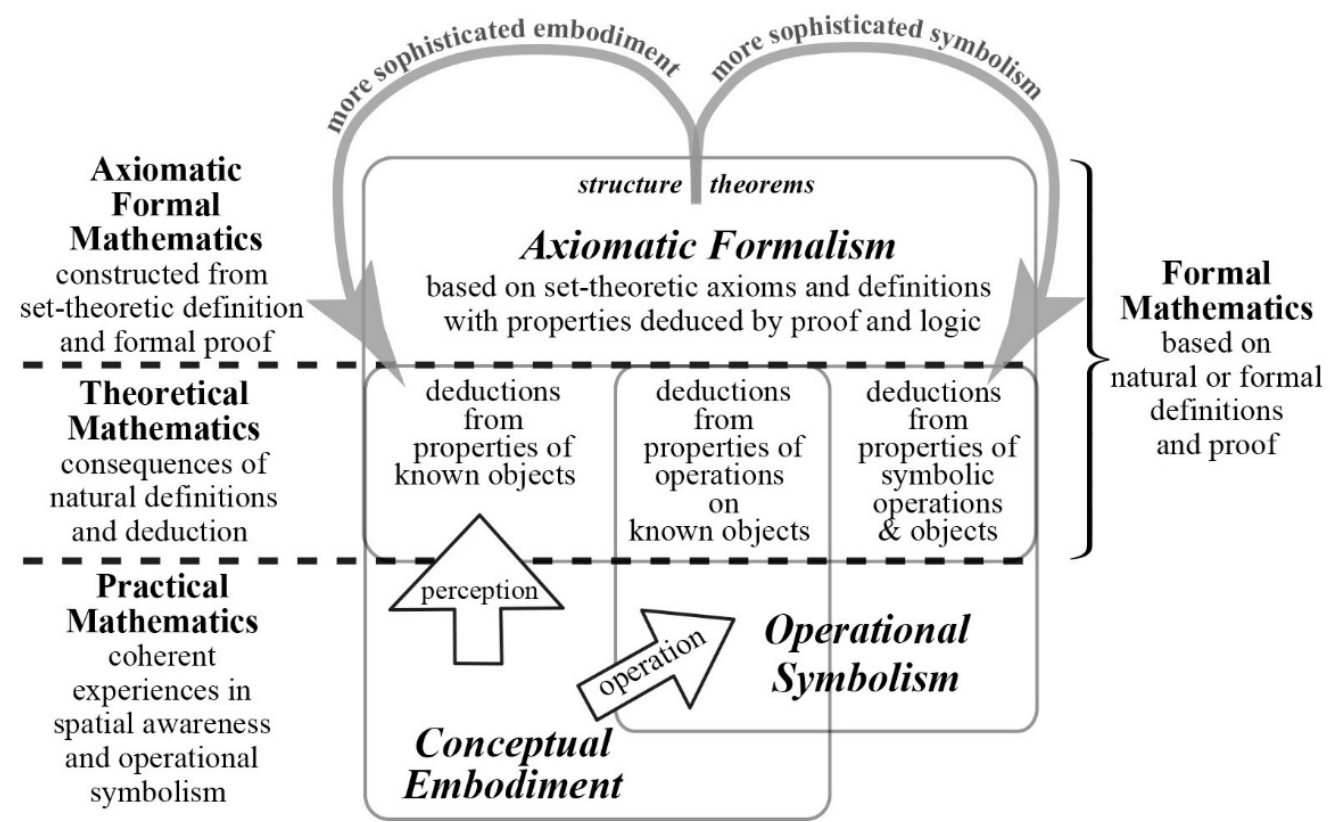

Figure 1. Three worlds of mathematics (Tall, 2020, p. 17)

Following the conceptual framework of Weigand (2014), we additionally want to emphasize the existence of differences in perspectives of teachers, on one side and the students' perspectives on learning processes on the other. Mathematics lessons from the students' perspectives often appear completely different compared to the teacher's point of view as empirical studies by Bauersfeld (1983), Coles (2015), Steinbring (2015), or Voigt (1983) show.

In 1990, Struve already pointed out that students are likely to perceive geometry as an empirical theory about visual materials and physical objects (e.g., folded and drawn figures), which in accordance with his theoretical framework which we will call empirical objects in the following. He describes the knowledge of students in empirical theories which are constituted by dealing with these empirical objects and aim at describing and explaining the phenomena of reality (Struve, 1990, p. 38). If students acquire mathematical concepts by dealing with empirical objects in a constructivist sense, they are likely to develop a so-called empirical belief system (Schoenfeld, 1985). We would like to point out that our goal is to describe the use of a learning environment to initiate targeted, theoretical concepts with a student.

According to this understanding, the empirical belief system can be characterized as a set of beliefs evolving from dealing with empirical objects with reference to mathematical concepts. In simple terms the reasoning process in empirical theories consists of two steps: an experimental one, to develop hypothesis and a deductive one to explain the phenomena. This is of course a reasonable approach to mathematics which becomes problematic, at least from a mathematician's point of view, if students do not use any (logical) reasoning but rather argue phenomenologically only on the basis of sensory perceptions, for example. Schoenfeld calls students that lack a sense for proofs in a logical sense "pure empiricists" (Schoenfeld, 1985, p. 160) - that is students who argue only on the basis of observations. "Any time they [pure empiricists] were asked about why something was true, the students' response was empirical and intuitive; proof was never mentioned" (Schoenfeld, 1985, p. 180).

In Tall's framework (2013) this is characteristic of practical mathematics which may observe relationships that are simultaneous but not yet have theoretical formulations that imply one property as a consequence of another in an explicit way. Tall (2020) with his three worlds of mathematics also provides a framework which can substantially contribute to the analysis of our data (see Figure 1).

In Tall's framework (2013) there is the world of (1) conceptual embodiment, which is based on human perceptions, actions and the development of mental images, and the world of (2) operational symbolism, where physical actions develop into mathematical procedures and symbols ("procepts"). Finally, there is the world of (3) axiomatic formalism, described by Tall (2013) as formal mathematical knowledge in axiomatic systems. For the latter we have to say that (3) does not occur in school. What happens in school is the development of practical mathematics and the formulation of theoretical definitions and deductions based on natural perception and reflection.

At this point the 3D printing technology comes into play. This technology makes the development as well as the production of empirical objects (manipulatives) in a variety of mathematical contexts quite easy and thus may facilitate empirical (or in Tall's terminology, "embodied") approaches to mathematical content.

Thereby we assume that students strongly tie their knowledge to the (empirical) context of its development (Bauersfeld, 1988). Research results show that a transfer of this knowledge, bounded to the contexts of its constructional process ("domain specific knowledge"), is a big challenge for mathematical learning in the sense of empirical theories (Bauersfeld, 1983). These domains of knowledge can be described in micro-worlds, e.g., in a money microworld (Lawler, 1980) or Domains of Subjective Experience (Bauersfeld, 1988) (see previous section: A Descriptive Perspective - Domain of Subjective Experience). According to Bauersfeld's framework of DSE it is reasonable to assume that students' knowledge may be tied closely to the 3D printed objects offered in mathematics lessons, especially as 3D printing technology offers the possibility to design these empirical objects individually. 


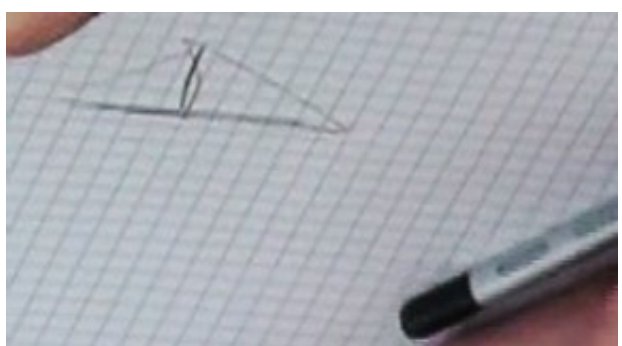

Figure 2. Paul's triangle

Table 1. Transcript of the student Paul on "base in a triangle"

Teacher \#00:49\# Paul-, you and Manuel discussed in the lesson.

Paul \#01:00\# mh-

Teacher \#01:01\# What was the problem?

[...]

Paul \#01:23\# I said that this is the base (he draws one side of the triangle side parallel to the bottom edge of his sheet of paper) and that the height. Manuel said that this is the base (he draws a triangle without any side parallel to an edge of the sheet of paper, see Figure 3) and that is the height.

$[\ldots]$

Paul \#01:44\# It doesn't matter, the result is the same, but it must always be at the bottom.
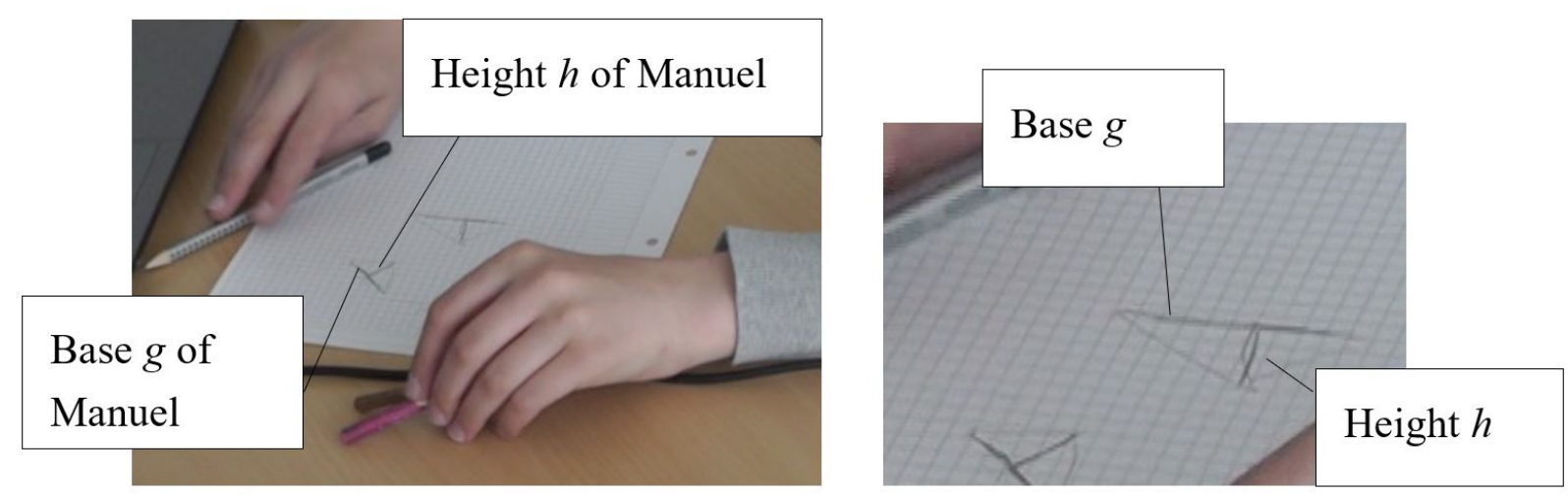

Figure 3. Paul - bases and heights of a triangle

Besides positive effects on learning and memorizing mathematical knowledge in this empirical way, this still inheres the difficulty to transfer this knowledge to other contexts - which we want to use in our learning setting to facilitate concept formation processes. To describe this for students we use in particular the concept of Domains of Subjective Experience (DSE) established by Bauersfeld (1983). These DSE provide a very clear analytical descriptive framework that explicates the aspect of domain specificity in the development of knowledge when dealing with empirical objects (in our example, figures in the drawing plane and 3D printed objects).

\section{ANALYSIS AND RESULTS - THE STUDENT PAUL}

\section{1st Phase of the Learning Environment}

In the 1st phase of the learning environment, Paul and his classmates had the task to draw three different triangles (the task was very open and students could choose the triangles for themselves), calculate the respective surface areas and then check and compare their results in pairs. For example, one group of students drew a a right-angled triangle and two other ones. Paul and his classmate also chose three triangles.

After that, both calculated the area of the triangle drawn first (Figure 2, Paul has already plotted the height in the triangle).

At first, Paul was not satisfied with the calculations and results of his partner Manuel (name changed). Since a noticeable discussion took place between both students in the class, Paul was once again asked about the situation by the author during the mathematics lesson with the purpose of describing and challenging his conceptual understanding regarding area calculations in triangles and the ensuing discussion with Manuel. It was striking, as the following sequence of conversation will show, that Paul always defined the 'lower' side - meaning the side pointing towards him, respectively the one which is parallel to the bottom edge of the page - of the triangle as the base. In this session he continuously drew triangles with one side parallel to the edge of the paper which he then defined as the base. The corresponding perpendicular line, through the opposite vertex finally constituted the height to him. The excerpt of the transcript in Table 1 illustrates his behavior. 


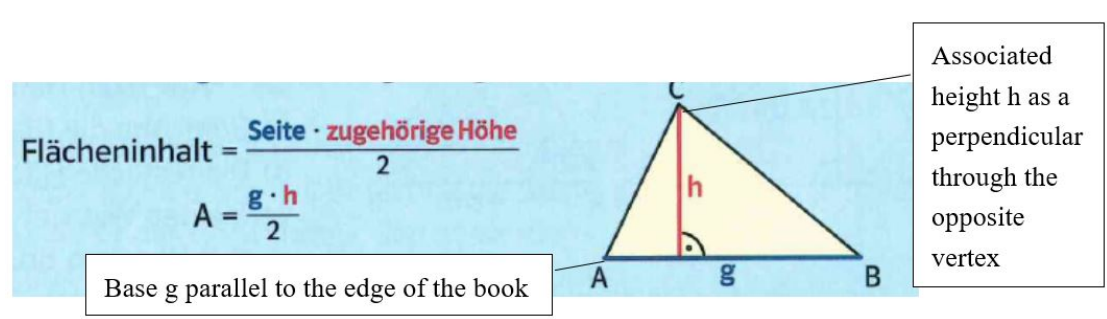

Figure 4. From Textbook "math live" for $8^{\text {th }}$ grade (Böer, 2017)
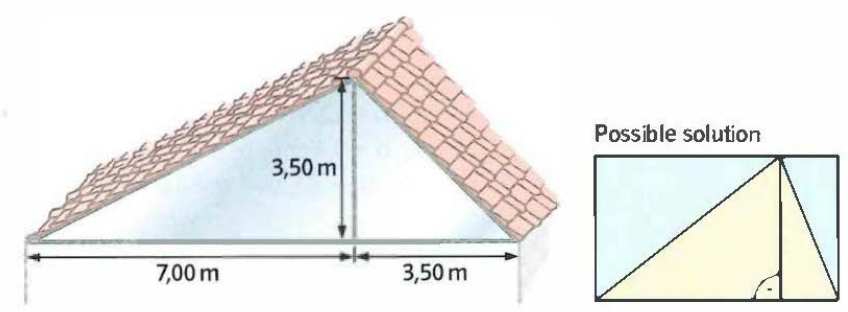

The front and rear gable walls of a house are completely glazed.

a) Think about how you can put together an easy-to-calculate area from the triangular windows at the front and back. b) Calculate the glass areas for a gable wall.

Figure 5. From Textbook "math live" for $8^{\text {th }}$ grade (Böer, 2017)

Striking for us was that Paul argued only on the basis of a sketch and did not need a precise construction of a triangle for his argumentation (as we would have expected following Schoenfeld's concept of "pure empiricism", as we will argue later in the article).

\section{An empirical understanding of bases}

According to Weigand et al. (2014) a height of the triangle is, a line that has one end point at the vertex of a triangle and the other at the perpendicular base point of the vertex with respect to the opposite side.

If we take a look at introductions to the topic surface areas of plane figures in textbooks, at least in German textbooks, we quite often find depictions of triangles with a defining character where the bases are oriented parallel to the bottom edge of the book (Kadunz \& Sträßer, 2008). In Figure 4, you find examples from textbooks.

The impression that the base is defined in reference to its orientation towards the bottom of the book is enforced by diagrams showing real application contexts. In Figure 5 the same book opens up the context of a triangular shaped roof of a house - the task is to calculate the size of the areas of the gable wall to cover them completely with glass.

These findings may indicate why Paul defines the base parallel to the bottom of the page as illustrated in Figure 3 . They are in accordance with research results regarding concept formation processes in the field of geometry (Struve, 1990). The following quote makes clear that even the terminology is bound to real application contexts: Knowledge, students construct in mathematics lessons is related to the reality; as "plumb-vertical" (lotrecht) and "horizontal" (waagerecht), are indeed concepts that are related to real objects and phenomena (Struve, 1990).

If we now take into account that learning is strongly bound to contexts ("DSE-concept" Bauersfeld, 1988) in which the knowledge is acquired, it is not at all surprising that Paul identifies the base with the side of the triangle which is oriented parallel to the bottom edge of the book or the sheet of paper. Keep in mind that people are constantly moving in the world and are making decisions in it - based on gravity. Paul's approach in this aspect, to define the side of the triangle which is oriented parallel to the bottom edge of the sheet of paper as the base is quite natural and understandable. In particular, in the framework of mathematics lessons oriented on textbooks, Paul's behavior appears to be natural, because even in the paradigmatic examples of the textbooks (Figures 4 and 5), one side of the triangle is defined as the base which is often parallel to the bottom edge of the textbook. This is especially true as orientation plays a decisive role in other mathematical contexts. If, for example, we think of the subject area analysis and the associated dealing with graphs of functions in coordinate systems (Figure 6), it becomes clear that orientation, as a small excursion to graphs of functions can illustrate, plays an important role in mathematics.

In Figure 6 we find the graph of a quadratic function. If we rotate it by $90^{\circ}$, the curve no longer describes the graph of a function. 


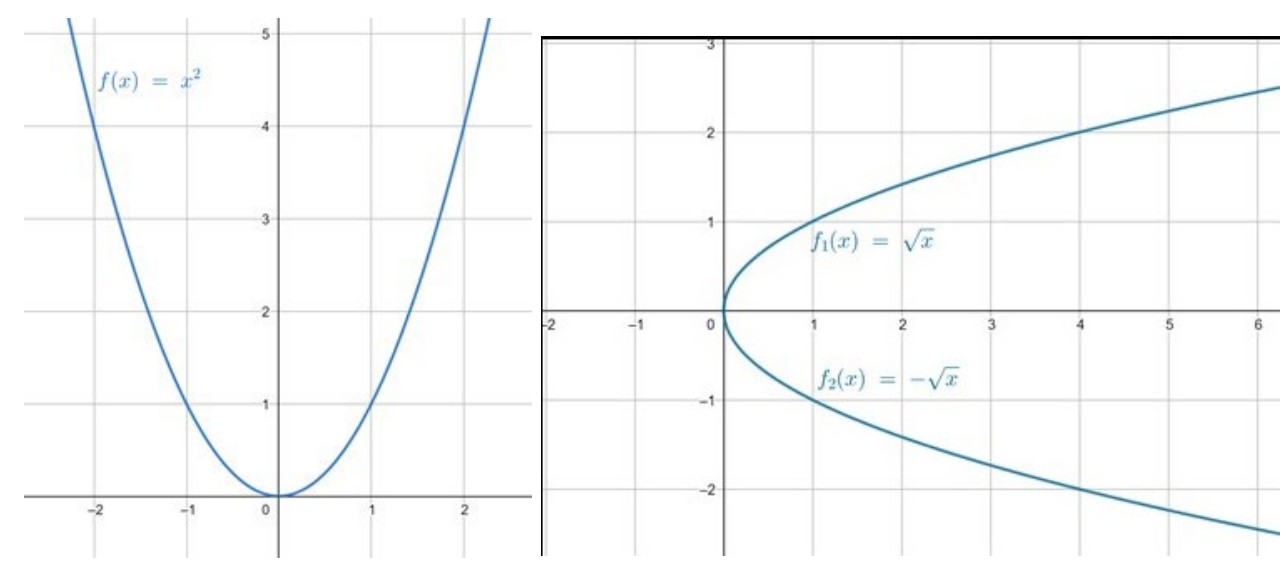

Figure 6. The graphs of the functions $f(x)=x^{2}$ and $f_{1}(x)=\sqrt{ } x$ and $f_{2}(x)=-\sqrt{ } x$

Table 2. Transcript of the student Paul - definition of the height in a triangle

Teacher \#03:12\# I have one more question: What exactly is a height?

Paul \#03:25\# The height of the area... so if that is so (draws a square and a height in the square), this is the height. If so, e.g. (draws a quadrangle, above a triangle and a line from the bottom line to the opposite point), then that is the height, the highest point, to the lowest point.

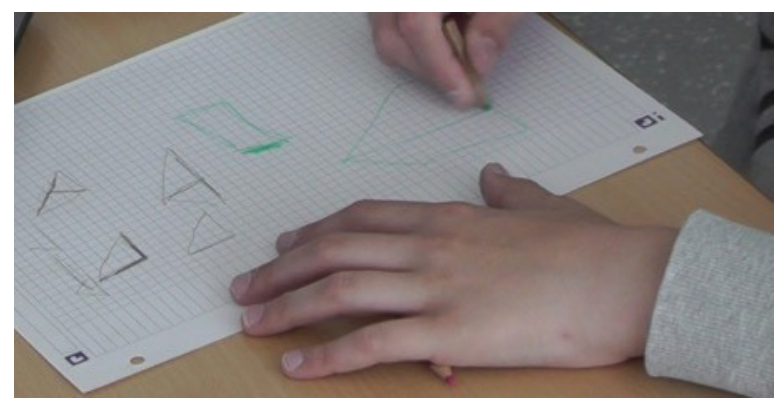

Figure 7. Paul and the height

Back to Paul's situation. It does not only have to be the side of the triangle which is oriented parallel to the bottom edge of the sheet of paper, additionally, it must be the side which is not only parallel but also the closest side of the triangle to the bottom. Paul shows an analog empirical understanding regarding the height of a triangle. After having drawn some triangles, Paul is asked for his notion of the height (See Table 2).

The height of an area means that a height is not only assigned to a certain base, but uniquely to a special surface regarding form and orientation (Figure 7).

For Paul it is always the line segment connecting the "highest point" (Table 2, in Paul's terms the point which is closest to the upper boundary of the drawing sheet, regarding his position to the sheet) and the "lowest opposite point" (Table 2, intersection point of perpendicular through the "highest point" and the base, which for him is parallel to the lower boundary of the drawing sheet) of a plane geometric figure. Paul's knowledge can be described in a Domains of Subjective Experience (DSE). In the sequences discussed here, Paul draws or sketches triangles on paper, with a ruler, or set squares in the drawing plane (= constituted by the drawing sheet in quite an empirical way including aspects of orientation). In this DSE, the base of a polygon is defined with respect to the orientation of the drawing sheet. It's clear that at a later stage this experience is a problematic metbefore (Tall, 2013). Of course, as a teacher, you want the student to be able to calculate the area of a triangle independently of the choice of the base and height.

As mentioned, students develop and formulate their theoretical knowledge (Tall, 2013 and Figure 1) in dealing with their surrounding reality (Struve, 1990). This, of course, includes the perception of falling objects and noting that they fall to the ground and it also includes the mental activities related to this perception. It seems almost natural that Paul includes the space that surrounds him in his argumentation - this is especially the case when "practical mathematics" (Tall, 2013 and Figure 1) is done in the classroom (in the learning environment). And in this reality, objects (because of gravity) fall to the ground (the direction of travel when an object is dropped) and are - in Paul case - oriented downwards, parallel to the bottom edge of the book/sheet of paper.

Of course, we do not want to convey the impression that we consider Paul's understanding to be thoughtless in any way. On the contrary, this example precisely shows what meaningful learning in empirical or practical contexts is all about and that Paul's behavior can be considered to be quite natural. 


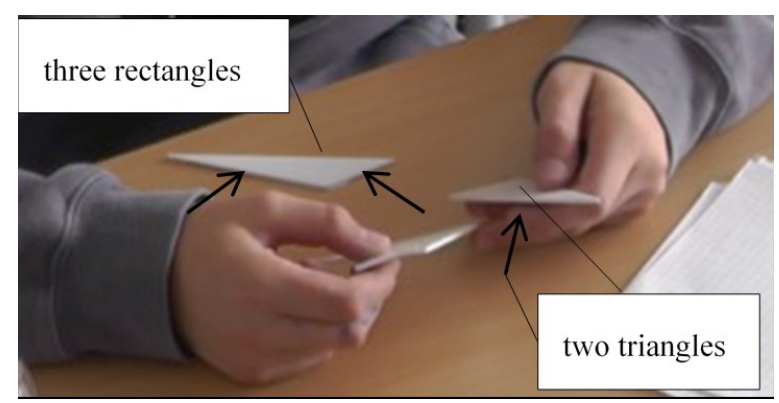

Figure 8. 3D printed triangular models in Paul's hands

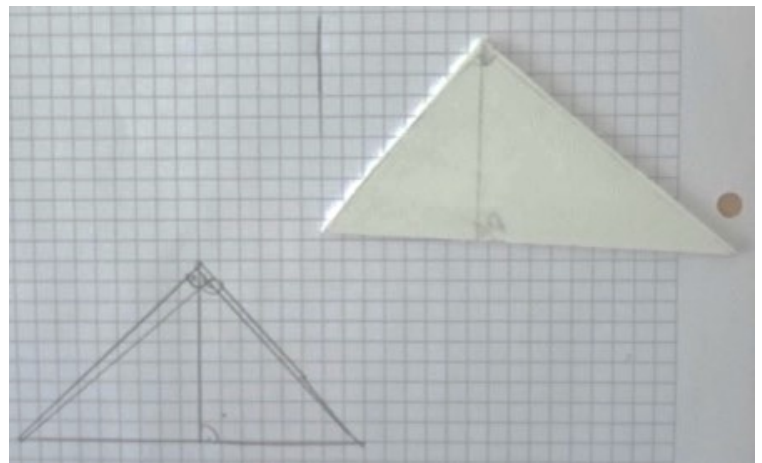

Figure 9.3D printed triangular model

\section{2nd Phase of the Learning Environment}

\section{Empirical knowledge in a different context}

Subsequently, we challenged Paul's notion of base and height with 3D printed triangular models (with the intention to challenge a problematic met-before). Through this learning environment, we wanted to facilitate the development of Paul's conceptual knowledge regarding the (non-)dependence of the surface area of a triangle on the choice of a certain pair of base and associated height. At the same time, we wanted to gain more insight into the stability and flexibility of knowledge acquired in a certain empirical context.

The 3D printed empirical objects in use clearly differ from plane figures drawn on a sheet of paper: They are three dimensional objects, actual prisms. Fortunately, Paul is quite familiar with working with 3D printed objects in mathematics lessons, as he is a member of a class which was accompanied by Math. Ed. researchers working with 3D printing technology in the classroom, for an entire year. Following an impulse of the teacher Paul takes different 3D printed triangular models in his hands (Figure 8).

At first, he points out to the teacher that these objects are geometric bodies consisting of two triangular surfaces and three rectangular surfaces. Here he makes clear that from his point of view, the 3D printed triangular models differ in important aspects from the triangles of the drawing plane - which is of course correct. They are, as he correctly describes, prisms which obviously do have an expansion in z-direction. Nevertheless, despite this observation, if we look at how he acts and speaks in the sequence as a whole, Paul (virtually) identifies the 3D printed triangular models (interestingly not only the surfaces) with the drawn plane figures. In the following we use the term 3D printed triangles to come close to his interpretation. Furthermore, Paul presents and explains his ideas on triangles with these empirical objects. First, he draws several triangles on the sheet of paper provided to him, drawing three different heights to the three different sides of the triangle. Then he chooses a triangle of the 3D printed selection offered by us. He takes one that looks quite like the one he has drawn. For this 3D printed triangle, he also draws the three different heights to three different sides (Figure 9).

At this moment, Paul connects different levels of representation (and maybe two DSEs too) in the sense of Bruner: the enactive mode with the 3D printed triangular models, and the iconic mode with the drawn triangles, as well as the drawings on the 3D printed triangular models (Bruner, 1971). In his world of embodiment, Tall (2002) connects Bruner's enactive and iconic modes a combination which Paul's approach clearly shows in this situation. For Paul the 3D printed triangles obviously serve both, an iconic and an enactive purpose in the context of heights and bases. On the one hand, he puts it on the drawing plane and deals with them as if they were plane figures of the drawing plane, on the other hand he touches them, lifts them up and rotates them in the room. From our point of view, the 3D printed objects could offer Paul a new access to the topic of triangles in geometry, as they open up the opportunity to be oriented and moved dynamically in three-dimensional geometric space (probably understood in an empirical/practical sense by Paul, e.g., the classroom). This challenges his prior definition of the base of the triangle referring to the boundaries of the drawing sheet (his empirical idea of the drawing plane). In this context, it is therefore worth mentioning that the student who is experienced in dealing with geometric figures drawn in the two-dimensional drawing plane, could now make use of three-dimensional objects that can be moved around in three dimensions, turned around, or turned over.

Interestingly, this is a problem encountered in Greek geometry where their sides and angles do not have a direction and yet the notion of congruent triangles includes the possibility of picking up a triangle and turning it over. 

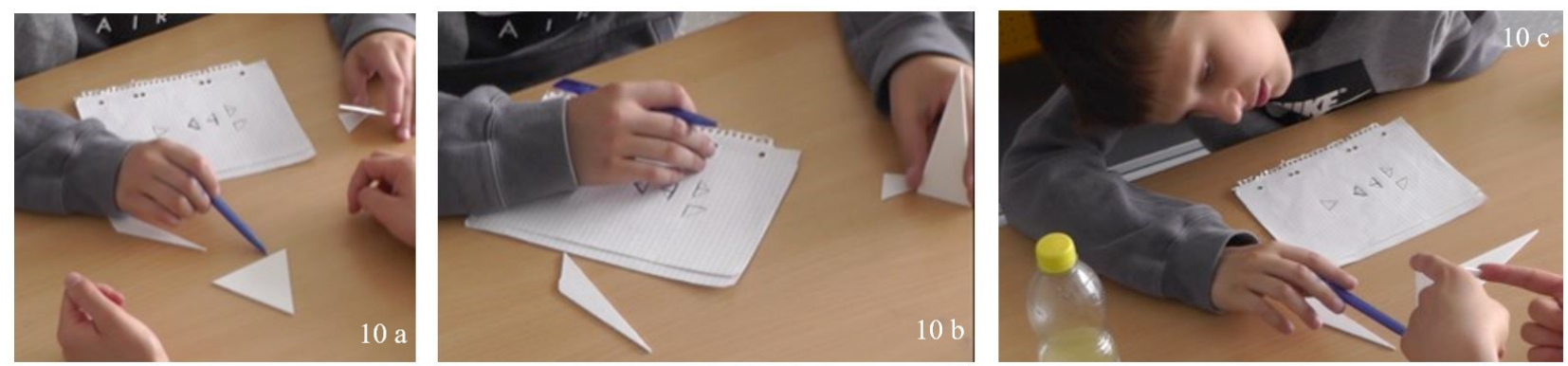

Figure 10. Paul's solutions

Table 3. Transcript of the student Paul - 3D printed triangular models and the base

Teacher \#02:31\# What is actually the base of a triangle?

Paul \#02:33\# (Picks up one of the 3D printed triangular models) The side on which it stands.

In this targeted learning environment, the goal of the teacher is to use the 3D printed triangles to induce a cognitive conflict (in the sense of Bauersfeld, 1988). The reason for that is to challenge (what might become) Paul's problematic met-before concerning his concept of area calculation in a triangle. Firstly (Figure 10a), the 3D printed triangle is laid flat on the table surface (and no longer on the sheet of paper). Paul now chooses a triangle side as the base, which is parallel to the bottom edge of the table. In the second picture (Figure 10b), the teacher, then Paul, places another 3D printed triangle with an edge on the table surface.

In the first two situations Paul works on this cognitive challenge as follows: his first solution (Figure 10a) is to place it with the triangular surface on the table. This offers to him the opportunity to orient one side of the triangle parallel to the edge of the table closest to him - this is what he consequently uses to define the base in the following. His second solution (Figure 10b) is to place the $3 \mathrm{D}$ printed triangle on one of the rectangular sides at an angle of $90^{\circ}$ to the tabletop.

In the third situation (Figure 10c), the teacher gives another impulse. This time, the teacher holds the 3D printed triangle in the hand in such a way that none of the edges is parallel to one of the coordinate axes ( $x-, y-, z$-axis). Paul solves this situation for himself by changing his perspective, moving his head, and orienting the 3D printed triangular model within his viewing axis (Figure 10c). These solutions exemplify how mathematical knowledge may be advanced by students (in empirical theories). Paul extends the range of application of his definitions by taking into account the empirical characteristics of a new 3D frame. Inspired by the learning environment and the targeted use of the material, the teacher goes on with challenging Paul's concept of area calculation in a triangle. The idea is to support him to overcome what might become a problematic met-before.

Another interesting finding is that Paul makes use of the 3D printed triangles to extend his definition of a triangle. While working with the 3D printed objects Paul makes clear that from now on a triangle is a "construction of an area with three different points" (quote from Paul, not in the transcript) instead of "something that has three points" which he said before. From an empirical point of view this specification (showing a development of knowledge) makes perfectly sense, as the drawing plane figure emphasizes the circumference whereas the (flat) 3D figure emphasizes the surface.

According to Pólya (1945), geometry can be seen as the right reasoning on wrong figures. Paul doesn't need precise mathematical constructions (Schoenfeld's concept of pure empiricism, see the section: theoretical framework). In contrast, he argues on the basis of sketches which indicates a sound understanding of mathematics to us - including the idea of the importance of reasoning based on logical conclusions not on perfect looking constructions. Unsurprisingly, this understanding is clearly grounded in empiricism as the knowledge is developed on the basis of empirical characteristics of the figures and in particular with respect to changing points of reference regarding the location of base and height in the empirical planes and space - the concepts develop in the context of practical mathematics.

With regard to our initial quotations from Gopnik (2003), and Hefendehl-Hebeker (2016) but also with a view on historical developments Paul's behavior appears to be as perfectly sound as an authentic mathematical activity.

\section{DISCUSSION AND CONCLUSION}

The goal of this article is to describe the use of a learning environment with the different context based on the usage of 3D printed objects to initiate targeted, theoretical concepts with the student Paul. To describe our case Paul and the exploratory processes in detail we make use of the descriptive approach of Domains of Subjective Experience (Bauersfeld, 1988). With the help of the DSE it is possible for us to show the development of the knowledge of the student Paul in the phase (1) and in the phase (2) of the learning environment (see section: Analysis and results - the student Paul). In this way it is possible to show that there is difficulty to transfer knowledge to different contexts. This and the idea of initiating a cognitive conflict (Bauersfeld, 1983) we used in our learning setting to facilitate concept formation processes with the student Paul. In doing so, we pursued the following research question, which is finally discussed below.

How to assist a student in a mathematical concept formation process - in the context of area calculations in triangles - with a specially designed learning environment based on the usage of $3 D$ printed objects? 
In the sense of empirical theories, teaching mathematics consistently in an object-oriented and practical (visual) way, and additionally promoting the development of concept formation as a mathematical activity, brings the student in a situation where he develops hypotheses, tries them out, and transfers them to other fields of application; thus engages in concept formation processes. Additionally, looking at Tall's framework of the "three worlds of mathematics" (Tall, 2013, and, e.g., Figure 1 in this paper): A problematic met-before (the belief only one pair of height and base would produce the area) arises in a context offered by textbooks. Later in the sequence, this understanding is challenged systematically by a change in context to 3D printed manipulatives which could easily be turned over in space in addition to being moved in the plane - without an a priori necessity of sophisticated mental operations beforehand. So, with the manipulatives we could offer new experiences to Paul and encourage him to construct more sophisticated ideas appropriate for further contexts.

As a case study for digital media, this study shows in detail that a sense-making use of 3D printing technology may support these kinds of learning processes. It opens up a range of possibilities for a time efficient, continuous and individualized use of empirical objects in the classroom. These objects, as our article can only give a very small account of, provide a whole set of means for students to engage in concept formation and definition processes themselves. It was a striking experience to the author of this paper and the teachers participating in the study that the student in this setting developed a substantial desire for conceptual negotiation processes in dealing with the 3D printed objects. There is of course potential for more interesting research issues here: For example, the discussion around the definition of a base with respect to a triangle oriented with one vertex to the lower boundary of the drawing sheet. Additionally, it is interesting to see if and how generalized knowledge can be developed working on very specific (individual) empirical objects produced by the 3D printer. In our case, it would be worth taking a more detailed look at Paul's cognitive conflicts regarding the difference between heights and sides in right-angled triangles.

Funding: No funding source is reported for this study.

Declaration of interest: No conflict of interest is declared by the author.

Acknowledgements: I would like to express my gratitude to Emeritus Professor of Mathematical Thinking David Tall for his guidance and support in completing this research paper.

\section{REFERENCES}

Bauersfeld, H. (1983). Subjektive erfahrungsbereiche als grundlage einer interaktionstheorie des mathematiklernens und -lehrens [Domains of subjective experience as the basis of an interaction theory of learning and teaching mathematics]. In $\mathrm{H}$. Bauersfeld, H. Bussmann, \& G. Krummheuer (Eds.), Lernen und Lehren von Mathematik: Analysen zum Unterrichtshandeln II (pp. 1-56). Aulis.

Bauersfeld, H. (1988). Interaction, construction, and knowledge: Alternative perspectives for mathematics education. In D. A. Grouws, \& T. J. Cooney (Eds.), Perspectives on research on effective mathematics teaching (pp. 27-46). Lawrence Erlbaum.

Böer, H. (2017). Mathe live 8: Mathematik für die Sekundarstufe I [Maths live 8: Mathematics for lower secondary level]. Klett.

Bruner, J. S. (1971). Über kognitive entwicklung [On cognitive development]. In J. S. Bruner, R. R. Oliver, \& P. M. Greenfield (Eds.), Studien zur kognitiven Entwicklung (pp. 21-53). Klett.

Burscheid, H. J., \& Struve, H. (2020). Mathematikdidaktik in rekonstruktionen: Grundlegung von unterrichtsinhalten [Mathematics education in reconstruction: A contribution to its foundation]. Springer. https://doi.org/10.1007/978-3-658-29452-6

Coles, A. (2015). On enactivism and language: Towards a methodology for studying talk in mathematics classrooms. ZDM, 47, 235246. https://doi.org/10.1007/s11858-014-0630-y

Dilling, F., \& Witzke, I. (2020). The use of 3D-printing technology in calculus education - Concept formation processes of the concept of derivative with printed graphs of functions. Digital Experiences in Mathematics Education, 6(3), 320-339. https://doi.org/10.1007/s40751-020-00062-8

Fetzer, M., \& Tiedemann, K. (2017). Talking with objects. CERME 10, Feb 2017. Dublin, Ireland.

Gopnik, A. (2003). The theory theory as an alternative to the innateness hypothesis. https://doi.org/10.1002/9780470690024.ch10

Hefendehl-Hebeker, L. (2016). Mathematische wissensbildung in schule und hochschule [Mathematical knowledge development in school and university]. In A. Hoppenbrock, R. Biehler, R. Hochmuth, \& H.-G. Rück (Eds.), Lehren und Lernen von Mathematik in der Studieneingangsphase (pp. 15-30). Springer. https://doi.org/10.1007/978-3-658-10261-6_2

Holland, G. (2007). Geometrie in der sekundarstufe: Entdecken - Konstruieren - Deduzieren: Didaktische und methodische fragen [Geometry in secondary school: Discovering - Constructing - Deducing: educational and methodological questions]. Franzbecker.

Kadunz, G., \& Sträßer, R. (2008). Didaktik der geometrie in der sekundarstufe I [Geometry in secondary school]. Franzbecker.

Krummheuer, G. (1984). Zur unterrichtsmethodischen dimension von rahmungsprozessen [On the methodological dimension of framing processes]. Journal für Mathematik-Didaktik, 84(4), 285-306. https://doi.org/10.1007/BF03339250

Lawler, R. W. (1980). The progressive construction of mind. Cognitive Science, 5, 1-34. https://doi.org/10.1111/j.15516708.1981.tb00867.x

MacDonald, M., Hill, C., \& Sinclair, N. (2020). The problem and potential of representation: Being and becoming. In S. Smythe, K. Toohey, D. Dagenais, \& M. Forte (Eds.), Rethinking language and literacy. Pedagogies with New Materialities. Routledge. 
Meyer, M. (2010): Wörter und ihr gebrauch - Analyse von begriffsbildungsprozessen im mathematikunterricht [Words and their use - Analysis of concept formation processes in mathematics lessons]. In G. Kadunz (Ed.). Sprache und Zeichen (pp. 49-82). Hildesheim: Franzbecker.

National Council of Teachers of Mathematics (2000). Executive Summary. Principles and Standards for School Mathematics. NCTM.

Panorkou, N., \& Pratt, D. (2016). Using Google SketchUp to develop students' experiences of dimension in geometry. Digital Experiences in Mathematics Education, 2(3), 199-227. https://doi.org/10.1007/s40751-016-0021-9

Pielsticker, F. (2020). Mathematische wissensentwicklungsprozesse von schülerinnen und schülern. Fallstudien zu empirischorientiertem mathematikunterricht mit 3D-druck [Students' processes of knowledge development in relation to empiricallyoriented mathematics classes using the example of the 3D printing technology]. Springer. https://doi.org/10.1007/978-3-65829949-1

Polya, G. (1945). How to solve it. https://notendur.hi.is/hei2/teaching/Polya_HowToSolvelt.pdf

Schoenfeld, A. H. (1985). Mathematical problem solving. Academic Press.

Schoenfeld, A. H. (2010). How we think: A theory of goal-oriented decision making and its educational applications. Routledge. https://doi.org/10.4324/9780203843000

Stake, R. E. (1995). The art of case study research. Sage.

Steinbring, H. (2015). Mathematical interaction shaped by communication, epistemological constraints and enactivism. ZDM, 47, 281-293. https://doi.org/10.1007/s11858-014-0629-4

Struve, H. (1990). Grundlagen einer geometriedidaktik [Foundations of school geometry]. Lehrbücher und Monographien zur Didaktik der Mathematik, 17. BI-Wissenschaftsverlag.

Taber, K. S. (2014). Methodological issues in science education research: a perspective from the philosophy of science. In M. R. Matthews (Ed.), International handbook of research in history, philosophy and science teaching (Vol. 3, pp. 1839-1893). https://doi.org/10.1007/978-94-007-7654-8_57

Tall, D. (2002). Using technology to support an embodied approach to learning concepts in mathematics. In L. M. Carvalho, \& L. C. Guimaraes (Eds.), História e tecnologia no ensino da matemática, vol. 1 (pp. 1-28). Cincia Moderna.

Tall, D. (2013). How humans learn to think mathematically. Exploring the three worlds of mathematics. Cambridge University Press. https://doi.org/10.1017/CBO9781139565202

Tall, D. (2020). Building long-term meaning in mathematical thinking: Aha! and Uh-Huh!.

Thompson, P. W. (1994). Concrete materials and teaching for mathematical understanding. Arithmetic Teacher, 41(9), 556-558. https://doi.org/10.5951/AT.41.9.0556

Tiedemann, K. (2016). “Ich habe mir einfach die Rechenmaschine in meinem Kopf gebaut!” Zur Entwicklung fachsprachlicher Fähigkeiten bei Grundschulkindern ["I just built the adding machine in my head!" For developing technical language skills in elementary school children]. Beiträge zum Mathematikunterricht 2016 (pp. 991-994). WTM-Verlag. http://homepages.warwick.ac.uk/staff/David.Tall/pdfs/dot2020b-aha-uhu.pdf

Vollrath, H.-J. (1984). Methodik des Begriffslehrens im Mathematikunterricht [Methodology of teaching concepts in mathematics lessons]. Klett.

Weigand, H.-G., Filler, A., Hölzl, R., Kuntze, S., Ludwig, M., Roth, J., Schmidt-Thieme, B., \& Wittmann, G. (2014). Didaktik der geometrie für die sekundarstufe I [Geometry in secondary school]. Springer. https://doi.org/10.1007/978-3-642-37968-0

Wittenberg, A. I. (1957). Vom denken in begriffen [About thinking in concepts]. Birkhäuser.

Witzke, I. (2009). Die entwicklung des Leibnizschen calculus: Eine fallstudie zur theorieentwicklung in der mathematik [The development of the Leibniz calculus: A case study on the development of theory in mathematics]. Franzbecker. 